\title{
Validation of Quantitative Analysis of Liquid Extract of Polygonum hydropiper L.
}

\section{NA Yunuskxodjayeva ${ }^{1}$, Sarvarova Dilfuza Musurmanovna ${ }^{1}$, NE Yunusxojiyeva $^{1}$ and BA Mukhamedgaliev ${ }^{2 *}$}

${ }^{1}$ Tashkent Pharmaceutical Institute, Civil Engineering, Uzbekistan

${ }^{2}$ Tashkent Institute of Architecture, Civil Engineering, Uzbekistan

*Corresponding Author: BA Mukhamedgaliev, Tashkent Institute of Architecture, Civil Engineering, Uzbekistan.
Received: October 22, 2021

Published: November 11, 2021

(C) All rights are reserved by $\mathbf{B A}$

Mukhamedgaliev., et al.

\begin{abstract}
This work is dedicated to the development and testing method for spectrophotometric analysis of a liquid extract of polygonum hydropiper. Quantitative analysis of the flavonoids in the liquid extract of polygonum hydropiper was carried out by acid hydrolysis by the amount of flavonoid glycosides.
\end{abstract}

Keywords: Polygonum hydropiper L. Plants; Validation; Method Specificity; Accuracy; Precision; Linearity; Repeatability; Spectrophotometric Method

Validated (validated) analysis methods should be used to assess the quality of drugs in accordance with modern requirements for the pharmaceutical industry.

Validation of analytical methods means to prove experimentally that this method is fully suitable for solving the problem.

The practical significance of validation is that in the process of developing new analytical methods, there will be an opportunity to identify their shortcomings in a timely manner and to significantly improve the method in the early stages. The practice of validation research shows that it is necessary to understand the essence of the method and strictly adhere to its indicators. As a result, the probability of errors when using the validated method is significantly reduced.

The process of validation of analytical methods for determining the amount of flavonoids proposed was carried out in accordance with the requirements established in the appropriate order in the samples of drugs [1-3].
Statistical analysis of the experimental data was performed using Microsoft Office Excel 2010. The correlation coefficient (r) was calculated using Microsoft Excel 2010.

This article is devoted to the validation of the results of spectrophotometric quantitative analysis of flavonoids in bitter thoron liquid extract. Experiments were carried out on the concentration of flavonoids in the «bitter liquid extract» relative to quercetin in 5 different concentrations. The method of quantitative analysis of the sum of flavonoids in the liquid extract of bitter thoron is based on spectrophotometric determination of the aglycone fraction by acid hydrolysis of the sum of flavonoid glycosides [4]. Hydrolysis of flavonoid glycosides was carried out in the presence of a solution of hydrochloric acid at a temperature of $100^{\circ} \mathrm{C}$.

Given that the hydrolysis of flavonoid glycosides proceeds at different rates, solutions of hydrochloric acid in different concentrations (from 2 to 10\%) were prepared in order to select the optimal hydrolysis conditions. The completeness of the hydrolysis process was monitored by the YuQX method. YuQX was carried out 
in the ascending method on chromatographic chambers saturated with a mixture of solvents ethyl acetate-chloroform-methanol (8: 1: 1) on plates UB $254(15 \times 15 \mathrm{~cm})$ «Silufol». Ammonia vapors and a solution of vanillin in sulfuric acid were used as the opening reagent. The completeness of the hydrolysis process was controlled by the absence of flavonoid glycoside stains on the chromatograms (only the aglycone stain is present) and the known UV-spectrum. The results obtained are presented in table 1 below.

\begin{tabular}{|c|c|c|}
\hline $\begin{array}{c}\text { Chloric acid } \\
\text { conc., \% }\end{array}$ & $\begin{array}{c}\text { Hydrolysis } \\
\text { time, min }\end{array}$ & $\begin{array}{c}\text { Aglycone } \\
\text { content, \% }\end{array}$ \\
\hline 2 & 30 & 0,42 \\
\hline 5 & 30 & 0,50 \\
\hline 10 & 30 & 0,56 \\
\hline 2 & 60 & 0,75 \\
\hline 5 & 60 & 0,64 \\
\hline 10 & 60 & 0,99 \\
\hline 2 & 90 & 0,89 \\
\hline 5 & 90 & 0,75 \\
\hline 10 & 90 & 0,99 \\
\hline
\end{tabular}

Table 1: Results of the effect of hydrochloric acid solution concentration on the hydrolysis of flavonoid glycosides.

The results from table 1 show that it is necessary to use a $10 \%$ solution of hydrochloric acid to complete the process of complete hydrolysis of flavonoid glycosides and to carry out the process for 60 minutes. Figures 1 and 2 show the UV-spectra of the aggregate of flavonoids in the bitter thoron liquid extract before and after hydrolysis.

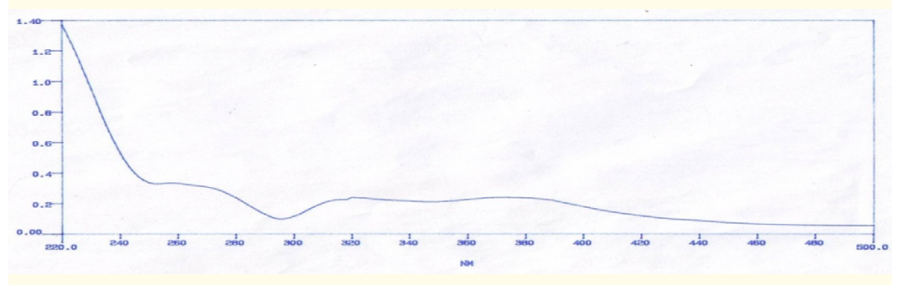

Figure 1: UV-spectrum of bitter thoron liquid extract before hydrolysis.

It was observed that the UV-spectra obtained after hydrolysis of the bitter thorn liquid extract were consistent with each other

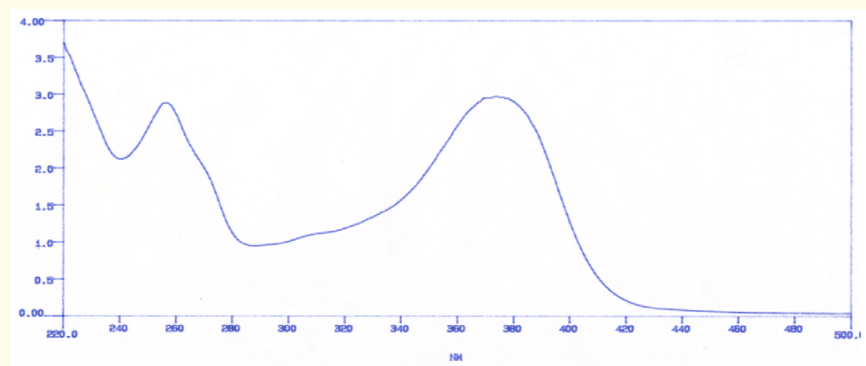

Figure 2: UV-spectrum after hydrolysis of bitter thoron liquid extract.

when compared with the spectra of the quercetin substance (370 $\mathrm{nm}$ ). Also, taking into account the fact that the aglycone part of the flavonoid glycosides of this drug is quercetin, quercetin was selected as a working standard sample in the method of quantitative analysis.

The amount of flavonois in the drug $(\mathrm{X}, \%)$ in relation to quercetin was calculated according to the following formula 1 :

$$
X=\frac{D_{0} \cdot m_{c m} \cdot 1 \cdot 25 \cdot 50 \cdot 25 \cdot 100}{D_{c m} \cdot 50 \cdot 100 \cdot V \cdot 5 \cdot 4}=\frac{D_{0} \cdot m_{c m} \cdot 12,5}{D_{c m} \cdot V}
$$

Where: - and - the optical densities of the quercetin working standard sample (ISN) and the solutions to be tested; V - amount of liquid extract obtained for analysis, $\mathrm{ml}$; - the exact gravity of the quercetin ISN, g.

Quantitative analysis of bitter thoron liquid extract is carried out as follows: $2.5 \mathrm{ml}$ of the drug is poured into a volumetric flask with a volume of $25 \mathrm{ml}$, made up to the mark with $95 \%$ ethyl alcohol and mixed.

Take $5 \mathrm{ml}$ of the resulting solution and put it in a roundbottomed flask with a volume of $250 \mathrm{ml}$, on top of which is added $10 \mathrm{ml}$ of a solution of $10 \%$ hydrochloric acid. Connect the flask back to the refrigerator and heat the boiling water over the bath for 1 hour. The solution is then evaporated to its initial volume, cooled in an ice-cold container for $15 \mathrm{~min}$, and filtered through a paper filter. The hydrolysis flask and the precipitate on the filter paper are rinsed 4 times with $10 \mathrm{ml}$ of water. Add $50 \mathrm{ml}$ of $95 \%$ ethyl alcohol heated to $50^{\circ} \mathrm{C}$ in portions to the flask, then dissolve 
the precipitate in the filter. The solution is collected in a $50 \mathrm{ml}$ volumetric flask, $4 \mathrm{ml}$ of the resulting solution is transferred to a $25 \mathrm{ml}$ volumetric flask, made up to the mark with $50 \%$ ethyl alcohol and mixed. The optical density of the resulting solution is measured on a spectrophotometer at a wavelength of $370 \mathrm{~nm}$, in cuvettes with a layer thickness of $10 \mathrm{~mm}$. In parallel, the optical density of the quercetin ISN solution is measured under the same conditions, using $50 \%$ ethyl alcohol as the reference solution.

Preparation of quercetin ISN solution. Dissolve 0.04g (net weight) of quercetin standard sample (FM 42Uz-0031-96), dried to constant weight at $130^{\circ} \mathrm{C}$, in a $50 \mathrm{ml}$ volumetric flask, dissolve in $95 \%$ ethyl alcohol, make up to the mark and mix. Take $1 \mathrm{ml}$ of the resulting solution, dilute with $50 \%$ ethyl alcohol in a $100 \mathrm{ml}$ volumetric flask and mix.

Preparation of $10 \%$ hydrochloric acid solution. Fill a $100 \mathrm{ml}$ volumetric flask with $50 \mathrm{ml}$ of water, add $7 \mathrm{ml}$ of concentrated hydrochloric acid, make up to the mark with water and mix.

The results of the quantitative analysis of bitter thoron liquid extract are given in table 2 below.

\begin{tabular}{|c|c|c|c|c|c|c|}
\hline $\mathbf{X}_{\mathbf{i}}, \mathbf{\%}$ & $\overline{\tilde{O}}, \mathbf{\%}$ & $\mathbf{f}$ & $\mathbf{S}^{2}$ & $\mathbf{S}$ & $\mathbf{\Delta} \tilde{O}$ & $\bar{\varepsilon} \mathbf{\%}$ \\
\hline $\mathrm{X}_{1}=0,249$ & 0,252 & 4 & 0,000026 & 0,00517 & 0,0016 & 2,54 \\
$\mathrm{X}_{2}=0,245$ & & & & & & \\
$\mathrm{X}_{3}=0,256$ & & & & & & \\
$\mathrm{X}_{4}=0,257$ & & & & & & \\
$\mathrm{X}_{5}=0,255$ & & & & & & \\
\hline
\end{tabular}

Table 2: The results of the analysis and the metrological description of the method $(n=5 ; P=95 \% ; t(p, f)=2,78)$.

According to table 2, the content of flavonoids in the bitter thoron liquid extract averaged $0.25 \%$ relative to quercetin, and the relative error of the spectrophotometric method was $2.54 \%$. The detection time did not exceed two hours.

The developed method included the amount of VFM of bitter thoron liquid extract in the analysis section and determined that the total amount of flavonoids in the liquid extract was not less than $0.2 \%$. The obtained results were checked for validation indicators: method specificity, linearity, accuracy, repeatability and precision.

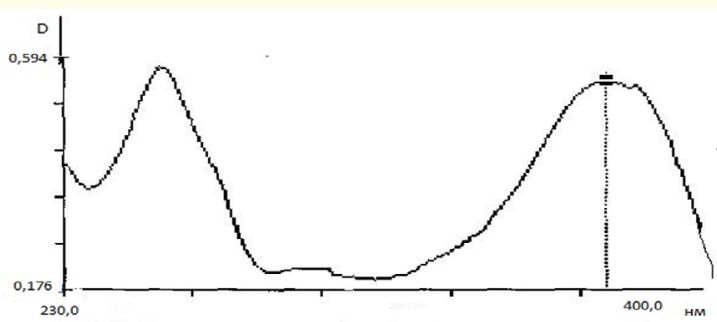

Figure 3: Quercetin UV-spectrum.

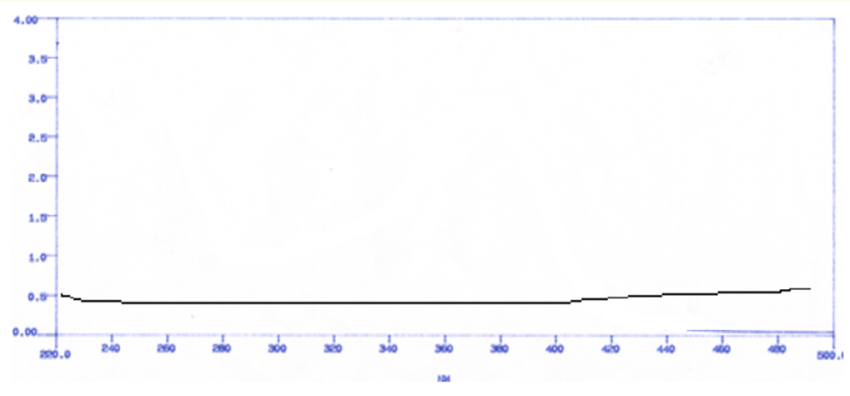

Figure 4: Spectrum of placebo solution.

From the data in figures 3 and 4, it can be seen that the spectra of the bitter thoron liquid extract and the spectra of quercetin are compatible, with their maximum absorption wavelengths corresponding to 370-373 $\mathrm{nm}$. This confirms that other compounds that may be included in the drug during the extraction of plant raw materials do not affect the results obtained, and thus the specificity of the method of analysis developed.

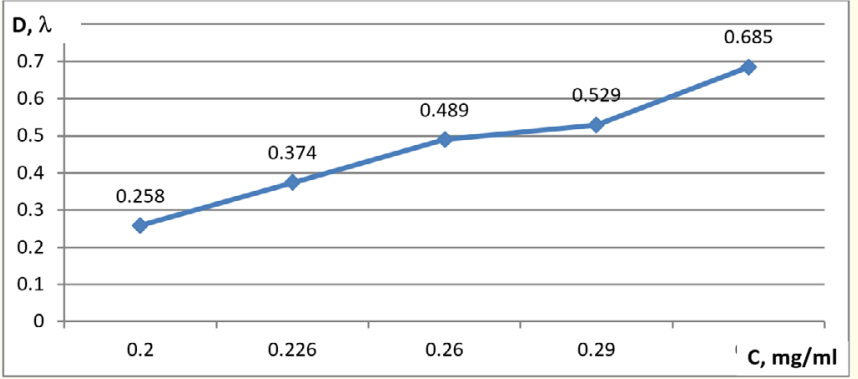

Figure 5: Graphical relationship of the total amount of flavonoids in the liquid extract of bitter thoron with the optical density. 
Based on the results obtained, it was determined that there is a directly proportional relationship between the analytical signal (optical density) and the concentration of the sum of flavonoids in the method developed in the selected range. All correctly proportional dependencies have a high correlation coefficient - $r$ $=0.9912$.

As can be seen from Figure 5, all identified experimental points are located on a single straight line. The value of the correlation coefficient was as follows: 0.9912 and it was in the range of 0.98 $\leq \mathrm{R}^{2} \geq 1.0$, and it was found that the linear correlation sample concentration was in the range of $2.02-3.02 \mathrm{mg} / \mathrm{ml}$.

Thus, the results obtained showed that the developed method adheres to the correct linearity in the range of concentrations used. Data from 1 and 2 analytical and interlaboratory studies confirmed the absence of systematic errors. Hence, the developed analysis method was found to be precision under intermediate and reversible conditions.

\section{Conclusion}

As a result of the research, the validation parameters of the developed method were confirmed: specificity, linearity, accuracy and precision. This leads to the conclusion that this method can be included in a pharmacopoeias article. The developed method included the amount of VFM of bitter thoron liquid extract in the analysis section and determined that the amount of flavonoids in the liquid extract was not less than $0.2 \%$ of the total amount.

\section{Bibliography}

1. Beregovyx VV., et al. "Validatsiya v proizvodstve lekarstvennyx sredstv". Pod red. chl.korr. RAMN, prof. V. V. Beregovyx. Izdatelskiy dom "Russkiy vrach" (2010): 286.

2. Perev JI., et al. "Validatsiya analiticheskix metodik dlya proizvoditeley lekarstv: Typovoe rukovodstvo predpriyatiya po proizvodstvu lekarstvennyx sredstv, podgotovlennoe Federalnym soyuzom farmproizvoditeley Germanii (VAN)". Littera (2008): 132.

3. Arzamastsev A P., et al. "Validatsiya analiticheskix metodov". Pharmacy 4 (2006): 8-12.
4. Kashchenko NI and Olennikov DN. "Spectrophotometric analysis of phenolic compounds calendula medicinal (Calendula officinalis L.). Revizionnoe issledovanie sushchestvuyushchix metodov". Butlerovskie Soobshcheniya. Kazan 37.1 (2014): 146-155.

Volume 3 Issue 12 December 2021

(C)All rights are reserved by BA Mukhamedgaliev., et al. 